\title{
Catalysis

\section{MINI REVIEW}

Check for updates

Cite this: Catal. Sci. Technol., 2019, 9, 47

Received 17th October 2018,

Accepted 13th November 2018

DOI: $10.1039 /$ c8cy02156b

rsc.li/catalysis

\section{Introduction}

Catalysis is the core method of producing commodity chemicals on the large scale and is getting more and more important in the synthesis of fine chemicals either in preparing intermediates or the final products. Catalysts in the same phase as the reactants and/or the products can be highly active and selective; however, their obvious disadvantage is that their recovery is tiresome and very often extremely difficult if it can be done at all. Heterogeneous catalysts, in general, may be less active and selective, but their recovery and regeneration are significantly easier. Nevertheless, there are heterogeneous catalysts, which are close to being as active and as selective as their homogeneous counterparts, albeit the selectivity inducing feature may be different. This feature is most often related to their intrinsic structure; they may provide a sterically constrained environment inducing various forms of shape selectivities. Moreover, catalytically active organic molecules, metal complexes may be immobilized in/on these materials, and, thus, the activity and selectivity of these molecules can be combined with shape selectivity providing easy recovery and regeneration at the same time. On top of that, the solid host may be catalytically active itself, thus, highly selective cascade reactions may also occur providing complex molecules as products.

\footnotetext{
${ }^{a}$ Institute of Pharmaceutical Chemistry, University of Szeged, Eötvös u. 6, H-6720 Szeged, Hungary. E-mail: otvossandor@pharm.u-szeged.hu, fulop@pharm.u-szeged.hu; Tel: (+36) 62545 768, (+36) 62545562

${ }^{b}$ MTA-SZTE Stereochemistry Research Group, Hungarian Academy of Sciences, Eötvös $u$. 6, H-6720 Szeged, Hungary

${ }^{c}$ Department of Organic Chemistry, University of Szeged, Dóm tér 8, H-6720 Szeged, Hungary. E-mail: palinko@chem.u-szeged.hu; Tel: +36 (62) 544288

${ }^{d}$ Material and Solution Structure Research Group, Institute of Chemistry,

University of Szeged, Aradi Vértanúk tere 1, H-6720 Szeged, Hungary

${ }^{e}$ Institute of Chemistry, University of Graz, NAWI Graz, Heinrichstrasse 28,

A-8010 Graz, Austria
}

In this minireview, we intend to provide examples for the above-mentioned phenomena choosing the class of layered materials of catalytic relevance. Layered double hydroxides are the first group chosen, since these substances are frequently applied as catalysts for producing fine chemicals. Although the majority of works concern the use of their calcined and thus non-layered forms, there are ample examples for reactions, where keeping the layered form is advantageous either in the as-prepared form or after modification, which is most often the intercalation of various more or less bulky simple and complicated organic molecules, organometallic compounds in anionic forms and bulky inorganic anions. In the following sections, we review typical catalyst forms and typical reaction types including cascade reactions, but excluding photocatalytic reactions.

On the other hand, there are other classes of emerging layered materials, which can be designer catalysts, since they can also be modified with catalytically active species, or they may be catalytically active by themselves and their layered structure may also be advantageous. We have attempted to collect examples of these materials and their use in fine chemical syntheses.

\section{Layered double hydroxides}

\subsection{Structural features, synthesis and modification methods}

Layered double hydroxides (LDHs hereafter) are minerals found in nature; however, for applications, they are usually synthesized. The most common members of LDHs belong to the hydrotalcite supergroup. ${ }^{1}$ The name originated from the naturally occurring mineral, hydrotalcite $\left(\mathrm{MgAl}\left(\mathrm{CO}_{3}\right)-\mathrm{LDH}\right)$, discovered in the first half of the nineteenth century in Sweden. $^{2}$ The formula of hydrotalcite-like LDHs can be given as $\left.\left[\mathrm{M}^{2+}{ }_{1-x} \mathrm{M}^{3+}{ }_{x}(\mathrm{OH})_{2}\right]^{x+}\left[\mathrm{A}^{m-}{ }_{x / m} \cdot n \mathrm{H}_{2} \mathrm{O}\right)\right]^{x-}$, where $\mathrm{M}^{2+}$ and $\mathrm{M}^{3+}$ are di- and trivalent metal ions, $x=\mathrm{M}^{3+} /\left[\mathrm{M}^{2+}+\mathrm{M}^{3+}\right]$ and $\mathrm{A}^{m-}$ indicates the interlayer anions with charge $m \cdot{ }^{3}$ It can be obtained from brucite, a lamellar $\mathrm{Mg}(\mathrm{OH})_{2}$, where the divalent metal 
ions are partially and isomorphously substituted by trivalent (or, occasionally, tetravalent - e.g., $\mathrm{Zr}^{4+}, \mathrm{Sn}^{4+}$ ) cations. The excess positive charge of the layers is usually compensated by simple and exchangeable inorganic anions situated among the layers together with interlayer water molecules. ${ }^{4,5}$ Therefore, even the as-prepared ones are intercalated systems; nevertheless, hereafter we are going to call them pristine or asprepared LDHs. The variation of these anions gives numerous opportunities to modify the physical and chemical attributes of LDHs. The simple inorganic anions can be exchanged with more or less difficulty with bulky organic, inorganic or metalloorganic anions. Besides varying the interlayer anions, the ratio of the di- and trivalent metal ions in the layers can often be altered, and this may also modify the structural and catalytic characteristics of the actual LDH samples. ${ }^{6,7}$

In the last decades, LDHs were in the centre of research due to their peculiar layered structure allowing wide-ranging applications and to the relative ease of their availability and functional modification. They can be used as flame retardants, ${ }^{8}$ efficient adsorbents, ${ }^{9,10}$ models of supramolecular systems, ${ }^{11,12}$ and transport vehicles for delivering drug molecules. $^{13}$ They are good basic and occasionally redox catalysts, ${ }^{14}$ most frequently used after calcination (then their layered structure is lost). ${ }^{15-17}$

The main synthetic procedures for the preparation of these materials are the co-precipitation ${ }^{18,19}$ and the urea hydrolysis methods. ${ }^{20}$ The co-precipitation method is a solution-phase chemical method, in which aqueous solutions of $\mathbf{M}$ (II) and $\mathbf{M}$ (III) cations are treated with a basic solution, and at certain $\mathrm{pH}$ the solid LDHs precipitate. The urea hydrolysis method has the same principle with the difference that the urea solution provides the necessary $\mathrm{pH}$ value. With regulating the temperature (the hydrolysis of the urea is controlled by the temperature), a more precise $\mathrm{pH}$ value can be set and maintained.

The most efficient method for the mechanochemical synthesis of LDHs is the two-step milling operation. ${ }^{21}$ In the first step, the dry-milling step, the solid hydroxides of the M(II) and M(III) ions were applied. In the second step, a minute amount of water was added, and milling was continued. The addition of this minute amount of water was a must, because the hydroxide groups provided by the precursors were not sufficient for the LDH to form. This way many types of LDHs could be prepared..$^{22-24}$ The qualities of the LDHs could be increased using ultrasound during the wet-milling step. ${ }^{25-28}$ The syntheses were successful even on applying a "soft" mechanochemical treatment: co-grinding the constituents in a mortar with a pestle. ${ }^{29,30}$

Among other applications, LDHs are very often used in catalysis, mostly in base-catalysed reactions. Usually, they are employed as catalyst precursors. After calcination, the layered structure collapses and the catalytic activity of the resulting mixed oxide often increases, because of the presence of many defects in its structure.

Significantly rarer though, LDHs in their pristine state as well as intercalated with more complex inorganic or organic anions were applied in synthetically useful reactions, for producing fine chemicals. We set out to collect the most important examples.

\subsection{Fine chemical syntheses using pristine LDHs as catalysts}

A successful application is the epoxidation of electrondeficient carbon-carbon double bonds of $\alpha, \beta$-unsaturated ketones (7 examples) using hydrogen peroxide as the oxidant (Scheme 1). This reaction proceeds over the most commonly used MgAl-LDH; ${ }^{31}$ however, CaAl-LDH as well as CaFe-LDH also proved to be efficient catalysts if the solvent was properly chosen. The yields were close to $50 \%$ if the solvent was formamide, cyclohexene or $n$-hexane. ${ }^{32}$ It was verified that preserving the layered structure was advantageous, since the pristine LDHs were more active than their calcined versions. Mechanistic details are known, and they are summarized in a recent review. ${ }^{33}$

Esterification of glycerol with lauric acid produced a mixture of monolaurinate, dilaurinate and trilaurinate over MgAl-LDH containing carbonate ions in the interlayer space. The increase in temperature favoured the glycerol conversion just as the high molar ratio of lauric acid to glycerol. The reaction was only selective for the monolaurinate at the initial stages. ${ }^{34}$ As-prepared LDH samples containing Zn(II), Ni(II) or $\mathrm{Mg}$ (II) as the divalent ion and $\mathrm{Al}$ (III) as the trivalent ion served as base catalysts in the transesterification reaction of ethylene carbonate with methanol to produce dimethyl carbonate and ethylene glycol (Scheme 2). ${ }^{35}$

Preserving its layered structure, $\mathrm{Cu}(\mathrm{II}) \mathrm{Fe}(\mathrm{III})-\mathrm{LDH}$ acted as an efficient heterogeneous catalyst (no metal ion leaching occurred) in the highly selective transformations of organic azides and alkynes in 1,3-dipolar cycloaddition reactions leading to valuable 1,2,3-triazoles (24 examples) in a continuous-flow system applying 50 to 100 bar pressure in the ambient to $100{ }^{\circ} \mathrm{C}$ temperature range (Scheme 3). ${ }^{36}$

$\mathrm{Cu}(\mathrm{II}) \mathrm{Fe}(\mathrm{III})-\mathrm{LDH}$ also performed superbly in the oxidative homocoupling reactions of aromatic amines (Scheme 4) as well as acetylenes (Scheme 5) in a flow reactor at moderate pressure and temperature even without auxiliary substances. $^{37}$ The catalyst maintained its extremely high activity for at least $15 \mathrm{~h}$ time on stream, and showed very high substance tolerance displaying outstanding selectivities (12 examples for both reactions).

Aldol condensation is an easy reaction in the presence of base catalysts, over as-prepared as well as reconstructed LDHs. ${ }^{38-41}$ The aldol dimerization and at higher temperature the condensation of furfural and acetone (Scheme 6) proceeded over the pristine MgAl-LDHs, albeit the calcined

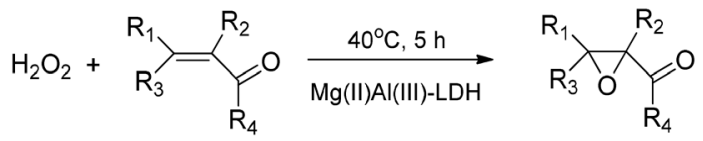

Scheme 1 Epoxidation of $\alpha, \beta$-unsaturated ketones catalysed with pristine $\mathrm{Mg}\left(\right.$ (I)Al(III)-LDH (7 examples). ${ }^{31}$ 


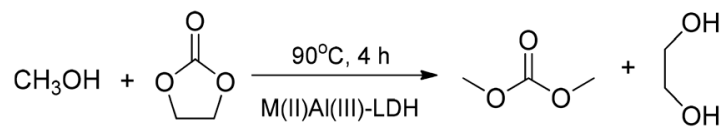

Scheme 2 Transesterification producing dimethyl carbonate and ethylene glycol catalysed by pristine LDHs (M(II):Zn(II), Ni(॥) or Mg(II)). ${ }^{35}$

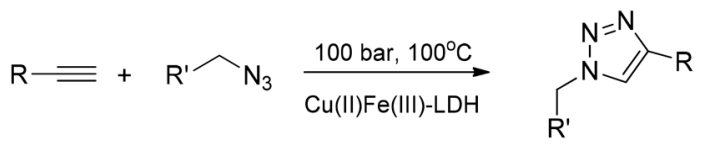

Scheme 3 1,3-Dipolar cycloaddition between terminal acetylenes and azides catalysed with pristine $\mathrm{CU}(\mathrm{II}) \mathrm{Fe}(\mathrm{III})$ - LDH in a flow system (24 examples). ${ }^{36}$

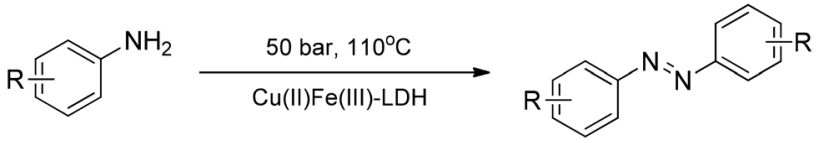

Scheme 4 Homocoupling reaction of anilines catalysed with pristine $\mathrm{Cu}(\mathrm{II}) \mathrm{Fe}(\mathrm{III})-\mathrm{LDH}$ in a flow system (12 examples). ${ }^{37}$

$$
\mathrm{R} \rightleftharpoons \frac{50 \mathrm{bar}, 130^{\circ} \mathrm{C}}{\mathrm{Cu}(\mathrm{II}) \mathrm{Fe}(\mathrm{III})-\mathrm{LDH}} \mathrm{R}=\mathrm{R}
$$

Scheme 5 Homocoupling reaction of terminal acetylenes catalysed with pristine $\mathrm{Cu}(\mathrm{II}) \mathrm{Fe}(\mathrm{III})-\mathrm{LDH}$ in a flow system (12 examples). ${ }^{37}$

LDHs were more active, probably due to the better accessibility of the basic sites. ${ }^{39-41}$

\subsection{Fine chemical syntheses using organocatalysts immobilized in/on LDHs}

Organocatalysts immobilized in CaFe-LDH were used in the cross-aldol dimerization condensation of benzaldehyde and acetone. Here the LDHs were applied as hosts for the intercalation of deprotonated proline (the most frequently used organocatalyst). ${ }^{42-44}$ The well-characterized intercalated structures were tested in the cross-aldol dimerization-condensation of benzaldehyde and acetone giving low (6\% (ref. 42)) through moderate (53\% (ref. 44)) to high (94\% (ref. 43)) enantioselective excess (ee) values. DL-Pipecolinate-CaFe-LDH had low activity in the cross-aldol dimerization-condensation reaction; however, its selectivity for condensation was very high. ${ }^{44}$ The nanohybrid material based on L-leucine (L-Leu) and MgAl-LDH was an active catalyst in the aldol dimerization reaction of cyclohexanone with benzaldehyde affording mainly the syn diastereomer (Scheme 7). ${ }^{45}$
Sixteen different amino acids were intercalated into MgAlLDH by the reconstruction method. The intercalated amino acid-LDHs catalysed the chemoselective $O$-methylation of phenol and $S$-methylation of thiophenol with dimethyl carbonate. The versatility of the intercalated system in the $O$-methylation of phenol derivatives was demonstrated with Leu-LDH via 20 examples (Scheme 8). ${ }^{46}$

Green efficient organocatalytic heterogeneous epoxidation of trans-methylcinnamate was achieved on MgAl-LDHintercalated levulinate using $\mathrm{H}_{2} \mathrm{O}_{2}$ /acetonitrile as the oxidant (Scheme 9). ${ }^{47}$ The levulinate (lev) was successfully intercalated by ion exchange and co-precipitation. The best performance was achieved at $40{ }^{\circ} \mathrm{C}$ and $24 \mathrm{~h}$ reaction time when the cinnamate conversion was $21.4 \%$ and the glycidate selectivity was $100 \%$.

The intercalation of thiamine pyrophosphate into $\mathrm{ZnAl}$ and MgAl-LDHs was performed by the co-precipitation procedure or the ion-exchange reaction. The guest anion adopted mono- and bilayer arrangements at lower and higher $\mathrm{pH}$ values, respectively. The hybrid materials were tested as biomimetic catalysts in the decarboxylation of pyruvic acid (Scheme 10) showing comparable activity to the homogenous system confirming that thiamine pyrophosphate can be safely loaded and stored in LDHs forming a novel bio-active hybrid material. ${ }^{48}$

The syntheses of the NAD coenzyme-CaAl-LDH composite was achieved by the dehydration-rehydration method applying aqueous ethanol or aqueous acetone. The intercalated composite proved to be an active catalyst in the oxidation of hydroquinone to 1,4-bezoquinoe in the presence of $\mathrm{H}_{2} \mathrm{O}_{2}$ (Scheme 11). ${ }^{49}$

\subsection{Fine chemical syntheses using metal complexes intercalated into LDHs as catalysts}

Metal complexes have already been incorporated into LDHs, and the early work has been reviewed. ${ }^{50}$ Complexes of various transition metal ions (Ni(II), Co(II), Fe(II), Ir(III), Mo(IV, VI), $\mathrm{Ru}(\mathrm{II})$, and $\mathrm{ReO}_{2}(\mathrm{v})$ ) have been incorporated among the layers of LDHs. Then and since then, only a few intercalated systems were used as catalysts. ${ }^{51,52}$

Some $\mathrm{Mn}$ (II) complexes were involved in the early ${ }^{50}$ and more recent ${ }^{53-59}$ contributions. Various prochiral olefins were epoxidized by oxygen or air over a Mn(III)-sulfonato-salen complex incorporated into ZnAl-LDH. ${ }^{53-58}$ The Mn-salen complex sandwiched between the layers of MgAl-LDH proved to be a stable recyclable catalyst in the $\mathrm{N}$-oxidation of picoline. ${ }^{59} \mathrm{~A} \mathrm{Mn}(\mathrm{II})$-porphyrin derivative complex intercalated into hydrophobically modified ZnAl-LDH was used for the

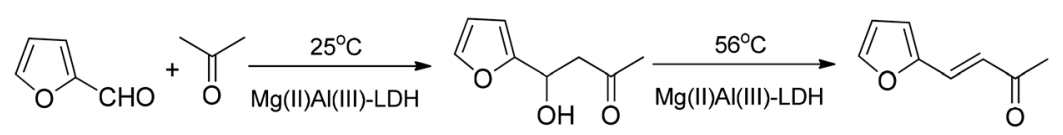

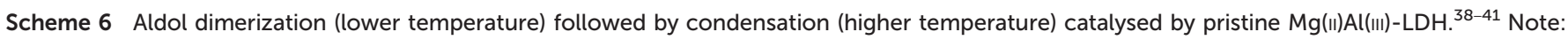
calcined $\mathrm{MgAl}-\mathrm{LDH}$ is a much better catalyst for these reactions. 


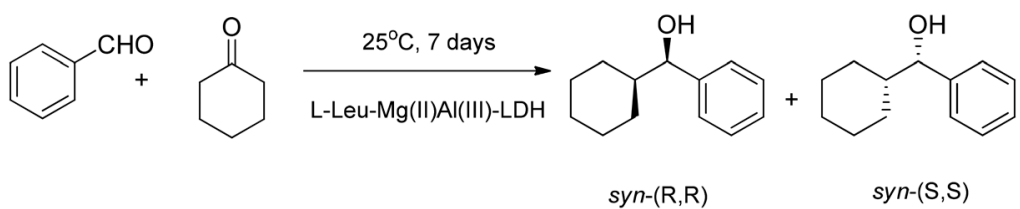

Scheme 7 The highly stereoselective aldol dimerization of benzaldehyde and cyclohexanone catalysed by L-Leu-MgAl-LDH. ${ }^{45}$ In the composite, the basic sites of LDH and L-Leu were responsible for the dimerization and stereoselectivity, respectively.

epoxidation of various alkenes (cyclohexene, heptylene, phenylethylene, 3-methyl-3-buten-1-ol, ethyl cinnamate and chalcone) with oxygen. ${ }^{60}$

The catalytic properties a $\mathrm{Cu}(\mathrm{II})-2,2$-bipyridine-5,5dicarboxylate complex intercalated into $\mathrm{ZnAl}-\mathrm{LDH}$ were studied in the oxidation of styrene, ethylbenzene and cyclohexane producing benzaldehyde, acetophenone and a mixture of cyclohexanol and cyclohexanone, respectively, and the catalyst could be used for the second time as well. ${ }^{61}$ The intercalated $\mathrm{Cu}$ (II)-sulfonato Schiff base complex-ZnAl-LDH composites were active in the glycerol to glyceric acid transformation, ${ }^{62}$ while the intercalated Ti(Iv)-Schiff base complexZnAl-LDH composite catalyzed the epoxidation of cyclohexene with $\mathrm{H}_{2} \mathrm{O}_{2} \cdot{ }^{63} \mathrm{Ti}(\mathrm{Iv})-\mathrm{L}$-tartrato complex anions could be introduced among the layers of MgAl-LDH in different steric arrangements depending on the conditions of the syntheses, and they were active catalysts in the enantioselective sulfoxidation of methylphenyl sulphide with an ee value of $58 \%$ at best (Scheme 12). ${ }^{64}$

It was possible to identify some papers dealing with $\mathrm{Fe}$ (III) complex-LDH systems and their catalytic uses. ${ }^{62,65,66}$ In the first two references, a variety of Schiff bases were the ligands. The catalytic properties of these intercalated complexes were tested in the selective oxidation of cyclohexane to a mixture of cyclohexanone and cyclohexanol ${ }^{65}$ or of glycerol to glyceric acid. $^{62}$ The Fe(III)-containing composites were active catalysts, but, in the latter reaction, the $\mathrm{Cu}(\mathrm{II})$-containing ones had superior performance. In ref. 66, one finds a report about the syntheses and characterization of $\mathrm{Fe}(\mathrm{III})$-porphyrine derivative complexes intercalated into $\mathrm{ZnAl}-\mathrm{LDH}$. The materials served as catalysts in the epoxidation of cyclooctene as well as in the hydroxylation of cyclohexane. In both reactions, the oxidant was iodosylbenzene $\left[\mathrm{PhI}(\mathrm{OH})_{2}\right]$ in situ formed from (diacetoxy)iodobenzene (Scheme 13). ${ }^{67}$

Recently, composites have been prepared where CaAl-LDH was the host and the anionic forms of $\mathrm{Mn}$ (II)-, ${ }^{68} \mathrm{Cu}(\mathrm{II})-{ }^{69} \mathrm{Fe}$ (III) ${ }^{70}$ and Ni(II)-amino acid (L-histidine, L-tyrosine, L-cysteine $)^{71}$ were the guests. The composites were tested in the oxidation reactions of cyclohexene and two oxidants (peracetic acid and $\mathrm{PhI}(\mathrm{OH})_{2}$ ) (Scheme 14). On using

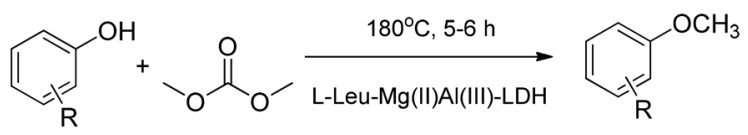

Scheme 8 L-Leu-MgAl-LDH catalysed chemoselective O-methylation of phenol derivatives (20 examples). ${ }^{46}$ peracetic acid the composites produced cyclohexene oxide (the epoxide) solely or overwhelmingly. The host was catalytically inactive; however, in the presence of the composites, the transformation of cyclohexene accelerated appreciably, and the conversions just slightly depended on the identity of the central ion or that of the ligand. The epoxide selectivity also increased considerably relative to the uncatalyzed transformation. The catalysts could be reactivated by simple rinsing with acetone, and they could work again with practically no changes in activities, moreover, the epoxide selectivity further increased, where it was possible.

Cyclohexene was oxidized, under similar conditions, with (diacetoxyiodo)benzene in aqueous acetone, too (the actual oxidant was the in situ formed $\left.\mathrm{PhI}(\mathrm{OH})_{2}\right)$. Interestingly, the selectivity was changed completely; the sole or predominant product became the cis diol. The added composites acted as catalysts, and they largely retained their activities even in the third recycling experiments, and again, they were only rinsed with the solvent after each run as the regeneration step. Diol was a primary product over the fresh as well as the recycled catalysts, since only the cis isomer was observed.

$\mathrm{Mn}$ (II)-containing catalysts ${ }^{68}$ were also tested in the oxidative transformations of allylic alcohol with peracetic acid as the oxidant. Here, epoxidation only occurred resulting in glycidol formation exclusively. Epoxidation did occur in the homogeneous reaction; however, the reaction rate/\% conversion substantially increased in the presence of the intercalated materials.

The $\mathrm{Cu}(\mathrm{II})-{ }^{69}{ }^{69}$ the $\mathrm{Fe}(\mathrm{III})^{-}{ }^{70}$ and $\mathrm{Mn}$ (II)-containing ${ }^{72}$ composites were probed in the Ullmann-type etherification (Scheme 15), ${ }^{73}$ and they were found to be efficient catalysts in these transformations, too. The composites also displayed very good recycling abilities. The conversions remained high even after the third recycling reaction. For regeneration, a simple rinse with toluene proved to be sufficient.

Recently, tetrasulfonic metallophthalocyanine (the cations were $\mathrm{Co}(\mathrm{II}), \mathrm{Mn}$ (II), $\mathrm{Fe}(\mathrm{II})$, and $\mathrm{Cu}(\mathrm{II})$ ) complexes could be intercalated into $\mathrm{ZnAl}-\mathrm{LDH}$, and these composites performed well in the epoxidation of styrene and its derivatives as well as a variety of alkenes (13 examples) ${ }^{74}$ and in the aerobic oxidation of alcohols to carbonyl compounds (Scheme 16; 23 examples with the Co(II)-containing composite). ${ }^{75}$

\subsection{Fine chemical syntheses using polyoxometalate-LDH com-} posites as catalysts

Bulky inorganic anions, such as polyoxometalates, could also be incorporated in-between the layers of LDHs with more or 


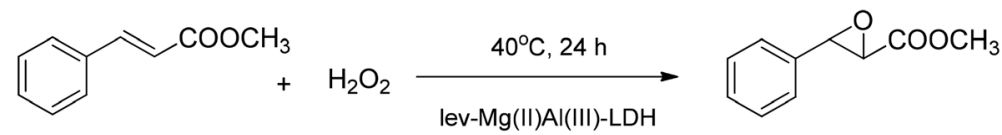

Scheme 9 Levulinate intercalated into MgAl-LDH keeps the stereochemistry of the starting olefin during epoxidation. ${ }^{47}$

less difficulty. The activity in this area as well their catalytic applications were reviewed not too long ago. ${ }^{76}$ These materials actively catalysed various oxidation, dehydrogenation, oximation and esterification reactions. An even more recent review of these composites, among other transformations, also describes a reaction where cooperation between the redox activity of polyoxowolframate (PW9) and the basic sites of the LDH occurred. ${ }^{77} \mathrm{~A}$ cascade reaction proceeded; benzylic alcohol was oxidized to formaldehyde by the guest polyoxometalate anion, then Knoevenagel condensation took place between this compound and cyano acetic acid ethyl ester over the basic sites of the Tris-modified ZnAl-LDH host (Scheme 17; Tris: tris(hydroxymethyl)aminomethane; for the original paper, see ref. 78).

In a very recent paper, the sulfoxidation (11 examples) and epoxidation (4 examples) reactions were reported to proceed over MgAl-ILs-La( $\left.\mathrm{PW}_{11} \mathrm{O}_{39}\right)_{2}$-LDH (ILs: 1-octyl-3-(3-triethoxysilylpropyl)-4,5-dihydro-imidazolium hexafluorophosphate) prepared by the exfoliation/assembly approach. ${ }^{79}$ The designed catalyst showed high efficiency and selectivity in both reaction types under mild conditions with excellent recycling abilities. The scaled-up experiments revealed that the catalyst retained its efficiency and robustness, which demonstrates the great potential of the catalyst for industrial applications.

\section{Metal phosphates and phosphonates}

Layered metal phosphates and phosphonates are promising materials due to their structural diversity and facile synthesis methods. ${ }^{80}$ They can easily be prepared from phosphoric acid or from the corresponding organophosphonic acids in the presence of various metal salts or complexes. ${ }^{81}$ Moreover, by controlling the synthetic conditions or by means of postsynthetic surface modifications, their structural and chemical properties can easily be fine-tuned for specific needs. Due to their remarkable stability, the most studied representatives are phosphates and organophosphonates of zirconium, but other metals, such as calcium, barium and strontium, were also employed as components of these layered materials. ${ }^{81,82}$

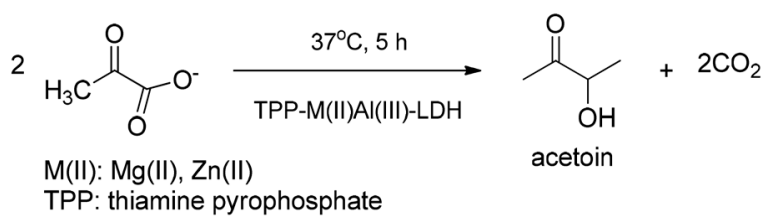

Scheme 10 Decarboxylative acyloin formation catalysed by thiamine pyrophosphate-LDH composites. ${ }^{48}$
As concerns catalytic applications in the field of fine chemical syntheses, the inherent acidity of metal phosphates and organophosphonates is particularly appealing. ${ }^{83}$ For example, Piermatti and co-workers reported the aza-Diels-Alder reaction of 2-cyclohexen-1-one with benzaldimines using layered $\alpha$-zirconium hydrogen phosphate as a heterogeneous Brønsted acid catalyst in water as an environmentally-benign reaction medium. ${ }^{84}$ Later, they also reported on aza-DielsAlder reactions between benzaldimines and Danishefsky's diene under solvent-free conditions using the same catalyst. ${ }^{85}$ Although the high yields obtained and the recyclability of the solid catalyst made these synthetic processes feasible, a significant amount of sodium dodecyl sulfate additive was required for efficient proton transfer, thus, for satisfactory synthetic results. Therefore, the same authors later prepared novel mixed zirconium hydrogen phosphate-alkyl and/or aryl phosphonate catalysts for the aza-Diels-Alder reaction of 2-cyclohexen-1-one with $N$-PMP- $p$-chloro-benzaldimine (Scheme 18). ${ }^{86}$ The role of alkyl and aryl groups in the organophosphonate components was to modulate the hydrophobicity of the catalyst. The modified catalyst surface together with the sterically constrained layered environment facilitated the contact of the reagents with the acidic catalyst sites, therefore, the aza-Diels-Alder reaction could efficiently be conducted without the need for any additives necessary for proton transfer. ${ }^{84}$

In another example, the alkylation of phenol by cyclohexanol was investigated over hexagonal $\alpha$-zirconium phosphate nanoparticles as an effective and recyclable solid acid catalyst under solvent-free conditions. ${ }^{87}$ The reaction conditions including the catalyst loading, reaction time and temperature were investigated thoroughly to achieve high conversion and excellent selectivity towards the formation of 4-cyclohexylphenol.

In a recent study, Piermatti and co-workers exploited potassium-exchanged zirconium phosphonate methyl and/or phenyl phosphonates as solid base catalysts in Knoevenagel condensations between various aldehydes and malononitrile or ethyl cyanoacetate (Scheme 19). ${ }^{88}$ The presence of the hydrophobic substituents of the phosphonate moiety in combination with the well-defined layered structure of the material

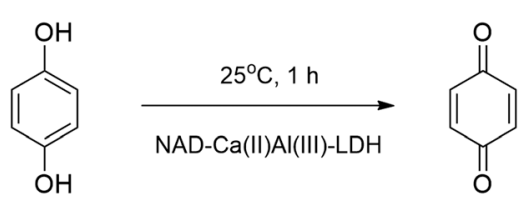

NAD: nicotinamide adenine dinucleotide

Scheme 11 Oxidation of hydroquinone catalysed with the NAD coenzyme intercalated into CaAl-LDH. ${ }^{49}$ 


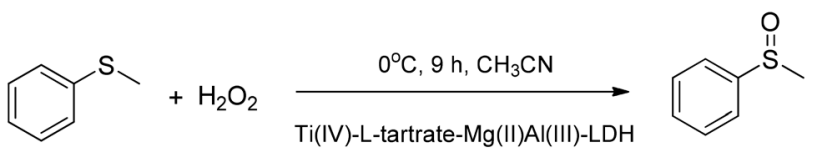

ee: $58 \%$

Scheme 12 Enantioselective sulfoxide formation catalysed with a $\mathrm{Ti}(\mathrm{IV})-\mathrm{L}$-tartrate complex intercalated into MgAl-LDH. ${ }^{64}$

$$
\mathrm{Phl}\left(\mathrm{OOCH}_{3}\right)_{2}+\mathrm{H}_{2} \mathrm{O} \rightleftharpoons \mathrm{Phl}(\mathrm{OH})_{2}+2 \mathrm{CH}_{3} \mathrm{COOH}
$$

Scheme 13 The in situ formation of iodosylbenzene. ${ }^{67}$

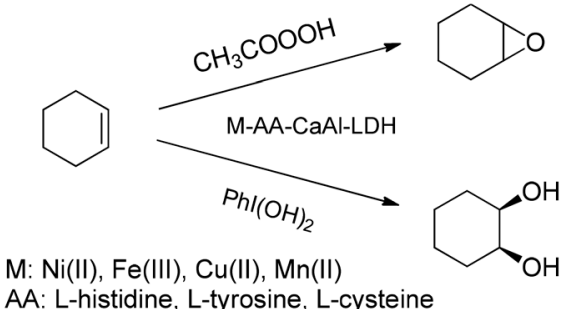

AA: L-histidine, L-tyrosine, L-cysteine

Scheme 14 Oxidant dependent reaction pathways in the oxidation of cyclohexene catalysed with metal ion-amino acid complexes intercalated into CaAl-LDH. ${ }^{68-71}$

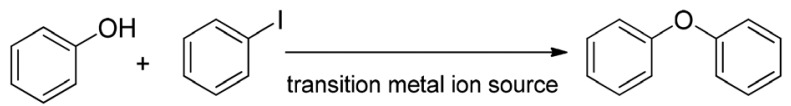

Scheme 15 The general scheme of the Ullmann-type etherification. ${ }^{73}$

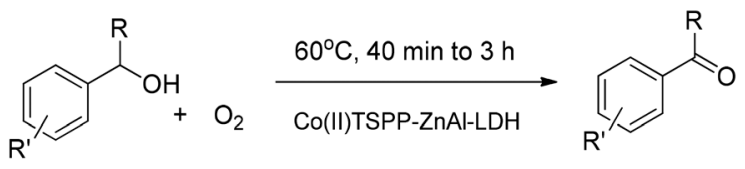

TSPP: tetra(4-sulfonatophenyl)porphin

Scheme 16 Aerobic oxidation of various alcohols (23 examples) catalysed with a Co(II)-tetra(4-sulfonatophenyl)porphin complex intercalated into $\mathrm{ZnAl}-\mathrm{LDH}^{75}$

proved beneficial as concerns reagent diffusion towards the basic catalytic sites. The best catalytic activity was found when applying methyl and phenyl as the hydrophobic substituents. In this case, the reactions could be carried out under mild conditions with catalyst loadings as low as $2-5 \mathrm{~mol} \%$.

Due to well-defined interlamellar distances, the layered structure of metal phosphates and phosphonates can sometimes be a limiting factor for synthetic applications with bulky substrates. ${ }^{89}$ In spite of that, layered $\alpha$-zirconium sulfophenylphosphonate derivatives were successfully utilized as solid acid catalysts for Biginelli-type reactions and also for Ferrier rearrangements involving bulkier starting materials and/or products, such as 3,4-dihydropyrimidin-2(1H)-one derivatives and multisubstituted sugars. ${ }^{90}$ The mild conditions

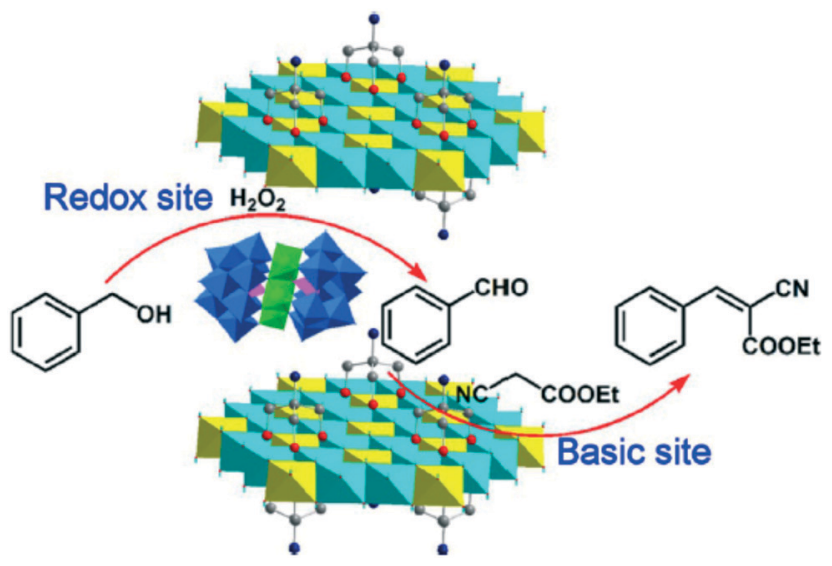

Scheme 17 Cascade reaction (oxidation followed by Knoevenagel condensation) over a covalently modified, polyoxometallate intercalated ZnAl-LDH composite (reproduced with permission from ref. 78).

and the recyclable nature of the catalysts made these processes of general applicability with negligible chemical waste.

Layered metal phosphates and phosphonates have also been used as supports for a large variety of catalytically active materials. ${ }^{81}$ Among supported catalysts, intercalated ones are the most interesting as concerns the scope of this survey, as they directly utilize the lamellar nature for immobilization purposes. $^{82}$ As an intriguing example, Lu and co-workers intercalated polyfluorinated palladium complexes into an $\alpha$-zirconium phosphate matrix for Sonogashira and Heck reactions (Scheme 20a). ${ }^{91}$ The authors managed to build the catalytic material into the layers directly, without the need for a pre-intercalation step, which is generally required to increase the interlayer distance. The palladium complex was bound into the zirconium phosphate carrier matrix by means of H-bonding via its short fluorine chain. Despite the moderately strong non-covalent forces between the catalyst and carrier, the supported material proved prominently robust, and allowed repeated catalytic cycles in both reactions studied. For Heck reactions, Vaccaro and co-workers later developed a technically simpler methodology by using palladium nanoparticles deposited onto a layered potassium $\alpha$-zirconium phosphate carrier (Scheme 20b). ${ }^{92}$ Reactions of a series of aryl iodides and methyl acrylate or styrene were studied in a $\mathrm{MeCN} / \mathrm{H}_{2} \mathrm{O}$ mixture as a green medium. After initial batch experiments, the synthetic methodology was translated into continuous-flow conditions. A mixture of the supported palladium catalyst in combination with a solid-supported base (PS-NEt ${ }_{2}$ ) was charged into a catalyst bed. After setting the optimal conditions, the reaction mixture was circulated until quantitative conversion was obtained. The flow method proved extremely beneficial in terms of waste production and allowed the isolation of the desired adduct without any purification steps.

Rocha and co-workers took advantage of the inherently lamellar nature of zirconium phosphate catalysts for finetuning the selectivities in the Baeyer-Villiger oxidations of 


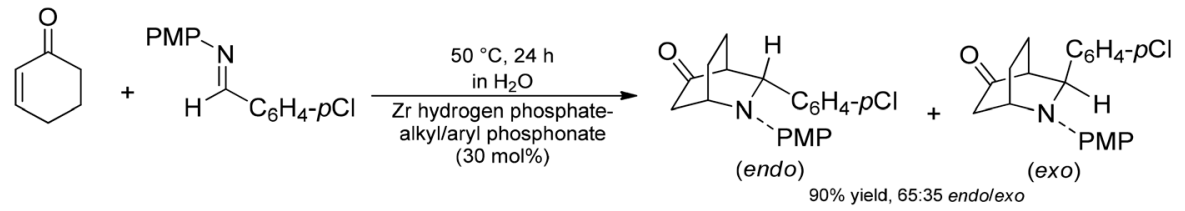

Scheme 18 Aza-Diels-Alder reaction of 2-cyclohexen-1-one with N-PMP-p-chloro-benzaldimin in the presence of a layered zirconium phosphate/organophosphonate catalyst. $^{86}$

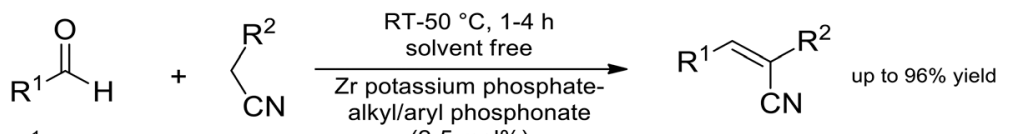

$\mathrm{R}^{1}$ : aromatic, aliphatic

$(2-5 \mathrm{~mol} \%)$

$\mathrm{R}^{2}$ : CN, COOEt

Scheme 19 Knoevenagel condensations in the presence of a potassium exchanged zirconium phosphate/organophosphonate as a solid base catalyst. $^{88}$

(a)

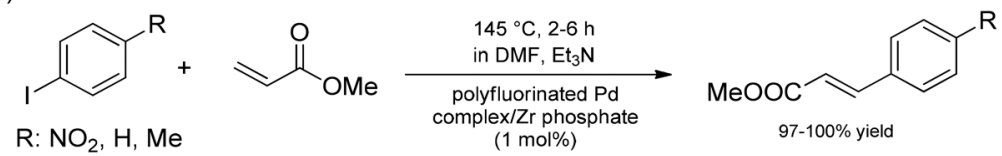

(b)

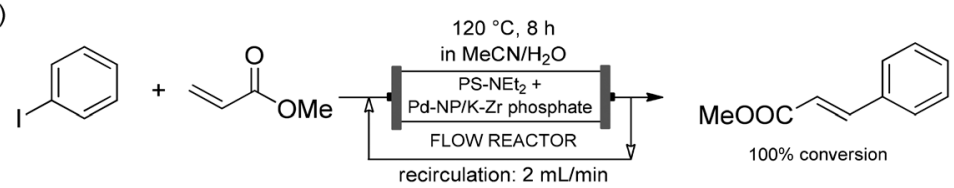

Scheme 20 Heck reactions (a) catalyzed by a polyfluorinated palladium complex intercalated into an $\alpha$-zirconium phosphate matrix, (b) catalyzed by palladium nanoparticles deposited onto a layered potassium $\alpha$-zirconium phosphate carrier in a fixed-bed continuous-flow system. ${ }^{91,92}$

various aromatic aldehydes with hydrogen peroxide. ${ }^{93}$ In the majority of such reactions of aldehydes, phenols are the desired products, which are obtained by hydrolysis of the initially formed formate esters. In order to maximize the selectivity to the phenolic products, the interlayer distance of the catalysts were adjusted via intercalation with ionic liquids of various sizes. With an optimal interlayer distance set, both the aldehyde component and the oxidizing agent could access the catalytic sites simultaneously leading to rapid formate ester formation without carboxylic acid side-products. On the easily available catalytic sites, the readily formed formate ester intermediates were efficiently hydrolysed into the desired phenols. Besides zirconium phosphates, layered $\mathrm{Sn}(\mathrm{Iv})$ phosphonates were also found effective as catalysts in Baeyer-Villiger oxidations of aromatic aldehydes using aqueous $\mathrm{H}_{2} \mathrm{O}_{2}$ as the oxidant. ${ }^{94}$

Khare and Chokhare intercalated Fe(III)-salen and $\mathrm{Cu}(\mathrm{II})$ salen into an $\alpha$-zirconium phosphate matrix and successfully utilized the heterogenized metal catalysts for the oxidation of cyclohexene using tert-butylhydroperoxide $(t \mathrm{BuOOH})$ as an oxidizing agent. ${ }^{95}$ The catalysts were prepared in a two-step process: first, the introduction of the catalytic metal by means of proton exchange, and then the intercalation of the ligand into the copper- or iron-exchanged layers. The as-prepared materials were characterized by means of various and complementary techniques, and they proved reusable in multiple catalytic reactions. In another report, $\mathrm{Mn}$ (III)-salen was immobilized on layered organic polymer-inorganic hybrid zinc phosphonate-phosphates and tested as catalysts for the asymmetric epoxidation of unfunctionalized olefins. ${ }^{96}$ In epoxidations of $\alpha$-methylstyrene and indene, the supported catalysts exhibited comparable or even higher enantioselectivities than the homogeneous catalyst. Importantly, the heterogeneous catalyst proved prominently stable and allowed the asymmetric epoxidations to be performed on a larger scale. Another example for intercalated catalysts is copper zirconium phosphate, as reported by Hajipour and Karimi. ${ }^{97} \mathrm{Cu}^{2+}$ was intercalated between the layers by means of a simple thermally-promoted ion-exchange reaction. The as-prepared material was successfully employed as a catalyst in selective oxidations and acetylations of various alcohols and phenols, which resulted in excellent product yields and an easy work-up procedure resulting from the heterogeneous conditions.

Layered zirconium phosphates and phosphonates were not only used as solid supports of metal catalysts, but they were also exploited as carriers of organocatalysts, typically via covalent forces. For instance, the research group of Piermatti immobilized L-proline on various zirconium phosphate/ phosphonate derivatives and investigated the catalytic capabilities of the heterogeneous material in direct asymmetric aldol reactions. ${ }^{98}$ For the catalyst synthesis, (4R)-4- 
(phosphonooxy)---proline was employed as alkyl phosphoric acid together with various amounts of methyl and/or phenylphosphonic acids in the presence of $\mathrm{ZrOCl}_{2}$. Gratifyingly, good conversions and ee values up to $96 \%$ were achieved in the $p$-nitrobenzaldehyde-cyclohexanone model reaction (Scheme 21). However, catalyst reusability was unsatisfactory due to hydrolysis of the phosphate ester bond, which linked the organocatalyst to the inorganic layer. The authors later modified their catalyst using a phosphonate linker resulting in significant improvement as concerns catalyst reusability. ${ }^{99}$ As another example, cinconidine was attached covalently onto the backbone of layered zirconium phosphonates as heterogeneous catalysts for the stereoselective addition of diethylzinc to aromatic aldehydes. ${ }^{100}$ The best catalyst investigated furnished excellent yields and good ee values, and it could be reused up to ten times without loss of activity and/or selectivity. Later, similar zirconium phosphonate-supported cinchonas were successfully employed as heterogeneous organocatalysts in the asymmetric aldol addition of $p$-nitrobenzaldehyde to cyclohexanone in an aqueous medium. ${ }^{101}$ 9-Amino-9-deoxy-epi-cinchonine was immobilized via covalent forces, thereby resulting in a robust and reusable catalytic system.

\section{Layered metal oxides}

Layered transition-metal oxides generally exhibit enriched ion-exchangeable sites within the interlayer space, and their most typical application in fine chemical syntheses is therefore solid acid catalysis in their proton-exchanged form. ${ }^{83}$ During such catalytic applications, chemical transformations often occur in the interlamellar space, which may give rise to various selectivity effects. For example, Domen and coworkers investigated various esterification reactions using $\mathrm{HNbMoO}_{6}$ as a layered metal oxide catalyst. ${ }^{102}$ They observed that the as-prepared material was able to catalyse esterification reactions of hydroxycarboxylic acids (e.g., lactic acid) only. Esterification of simple carboxylic acids alone was unsuccessful with the unmodified catalyst. However, upon intercalation with lactic acid, the interlayer space of the catalyst could be fine-tuned, and the esterification of simple carboxylic acids could successfully be carried out. The same layered solid acid catalyst was also found effective for Friedel-Crafts alkylations and for the hydrolysis of saccharides (Scheme 22). ${ }^{103}$ The high activity of the as-prepared material was explained by the ease of intercalation with the substrates and the strong acidity of the interlayer gallery. During the catalytic reactions, no catalyst exfoliation occurred and the catalyst preserved its original lamellar nature. For the same set of reactions, a layered tantalum molybdate catalyst $\left(\mathrm{HTaMoO}_{6}\right)$ was also investigated. ${ }^{104}$ It was found to exhibit stronger interlayer acidic sites than $\mathrm{HNbMoO}_{6}$, thereby resulting in higher catalytic activities in most of the reactions studied (e.g., Friedel-Crafts alkylation of anisole and toluene and hydrolysis of sucrose and cellobiose).

Molybdate-catalysed epimerization reactions are significant for the synthesis of rare sugars and pharmaceuticals. These reactions involve carbon skeleton rearrangement and are typically conducted under homogeneous catalytic conditions in acidic aqueous solution. ${ }^{105}$ In spite of this fact, Takagaki and co-workers, recently reported non-acidic $\mathrm{LiNbMoO}_{6}$ and strongly acidic $\mathrm{HNbMoO}_{6}$ to heterogeneously catalyse the epimerization of sugars including glucose, mannose, xylose, and arabinose in water as a green reaction medium. ${ }^{106}$ The metal oxide-mediated reactions gave good yields in short reaction times, and the heterogeneous catalysts could be reused without loss of activity. It was suggested that the outstanding catalytic activity was due to the easy accessibility of the $\mathrm{MoO}_{6}$ octahedra, which are building blocks of the layers.

Layered metal oxides were also shown to be useful as carriers of various metal catalysts. For instance, layered manganese oxides with deposited gold or silver nanoparticles were successfully employed as reusable catalysts in epoxidations of a variety of olefins (Scheme 23). ${ }^{107}$ Palladium supported on layered niobium oxide $\left(\mathrm{KNb}_{3} \mathrm{O}\right.$ and $\left.\mathrm{HNb}_{3} \mathrm{O}_{8}\right)$ was reported to efficiently catalyse the one-pot deacetalization/hydrogenation reaction of benzaldehyde dimethyl acetal to benzyl alcohol. ${ }^{108}$ It was revealed that both steps were strongly dependent not only on the presence of the catalytic metal but also on the acid strength of the catalyst.

\section{Layered metal silicates}

Metal silicates, especially aluminosilicate materials have attracted enormous attention in industrial and synthetic applications, which is mainly due to the success of synthetic zeolites as well-known examples. ${ }^{109}$ Multiple recent surveys can be found on the synthetic and catalytic applications of zeolite-based materials. ${ }^{110}$ Therefore, only metal silicates, which do not fit in the zeolite family will be discussed herein.

In a recent contribution, Szőllősi and co-workers demonstrated that a layered magnesia silicate, LAPONITE®, acts as

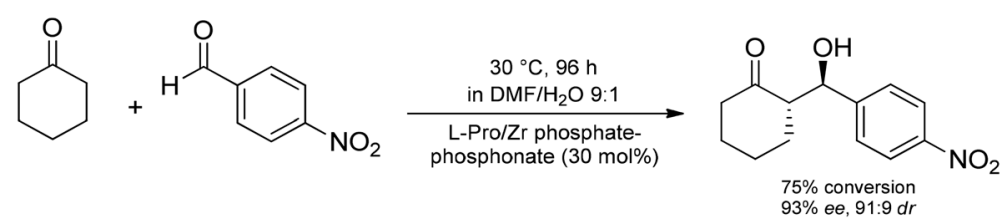

Scheme 21 Asymmetric aldol reaction between $p$-nitrobenzaldehyde and cyclohexanone catalyzed by zirconium phosphate-phosphonate supported L-proline. ${ }^{98}$ 


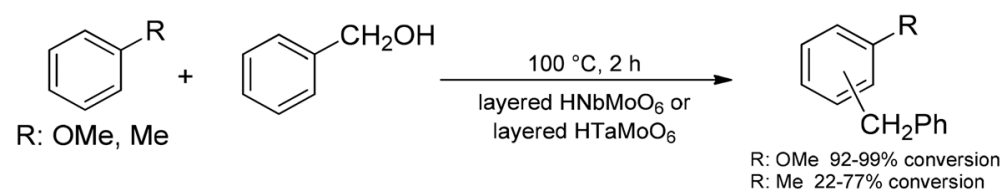

Scheme 22 Friedel-Crafts alkylation of anisole and toluene in the presence of layered niobium or tantalum molybdate solid acid catalysts. ${ }^{103 a, c, 104}$

a multifunctional organocatalyst carrier in asymmetric $\mathrm{Mi}^{-}$ chael additions of aldehydes to trans $\beta$-nitrostyrene derivatives (Scheme 24). ${ }^{111}$ It was revealed that LAPONITE $®$ served not only as a readily available catalyst support but as an additive; it also produced unprecedented enantioselectivity increase in the asymmetric reaction, thereby potentiating the effect of the amino acid-derived organocatalyst. The best results were reached by using L-proline as a supported catalyst. Another beneficial feature of the L-proline/LAPONITE® system is that it serves as an easily obtainable chiral heterogeneous catalyst without the need for laborious synthetic steps for immobilization.

Fan and co-workers prepared a layered organotitanosilicate by means of an evaporation-induced self-assembly process, and investigated its catalytic capabilities in the epoxidation of olefins using $\mathrm{H}_{2} \mathrm{O}_{2}$ as the oxidant. ${ }^{112}$ The catalytic hybrid material contained well-defined amounts of covalently linked phenyl groups, and therefore, it was proved to be superhydrophobic. As catalyst hydrophobicity can prevent poisoning of the active sites by water, the superhydrophobic nature of the hybrid material may explain its outstanding catalytic activity.

Layered hybrid materials based on ordered silicoaluminate sheets linked with organic pillars in the interlayer space were synthesized by a one-pot direct hydrothermal process without the need for initial swelling and/or pillaring the layered inorganic precursors. ${ }^{113}$ Upon facile exchange of intracrystalline sodium cations with protons, localised acid centres were formed contributing to excellent catalytic activities in Knoevenagel condensations between ethylcyanoacetate and various aldehydes (Scheme 25). The hydrothermal processes were later extended to the synthesis of bifunctional acid-base hybrid materials based on ordered organic aluminosilicate sheets with amino and sulfonic groups located in the interlayer space. ${ }^{114}$ The as-prepared materials proved efficient as heterogeneous acid, base or even as acid/ base catalysts in a diverse set of reactions, including Henry reactions, acetalization reactions and even a one-pot two-step reaction that involved acetal hydrolysis followed by Knoevenagel condensation.

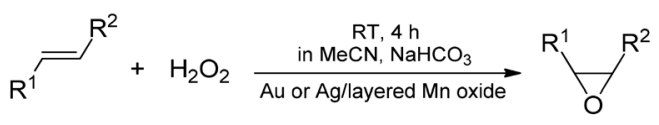

$93-100 \%$ conversion for aromatic olefin $31-63 \%$ conversion for aliphatic olefins

Scheme 23 Epoxidation of olefins catalysed by gold or silver nanoparticles deposited on layered manganese oxides. ${ }^{107}$

\section{Miscellaneous layered materials acting as catalysts}

Catalytic applications of layered materials which do not fit in the above categories are discussed in this subchapter. ${ }^{109 c}$

Arai and co-workers prepared a series of magnesiumcontaining mesoporous smectites as solid base catalysts for the reaction of $\mathrm{CO}_{2}$ with aminobenzonitrile to produce quinazoline-2,4 $(1 H, 3 H)$-dione, which is an important intermediate in the pharmaceutical industry (Scheme 26). ${ }^{115}$ The asprepared material exhibited significant catalytic activity in the cyclization reaction, moreover, upon functionalization of the layers with various alkali hydroxides, the basicity and thus the catalytic activity of the solids were further potentiated. As concerns catalytic activity, the incorporation of $\mathrm{NaOH}$ and $\mathrm{KOH}$ proved the best resulting excellent product yields. It was presumed that the catalytic reaction occurred between the layers of the solids, and the inherent basicity of the smectite materials and the hydroxide particles incorporated were co-operatively held responsible for the outstanding catalytic activities.

Organic-inorganic hybrid layered double sulfates were prepared by combination of aromatic/heterocyclic amines with $\mathrm{ZnSO}_{4} \cdot 7 \mathrm{H}_{2} \mathrm{O}$ under slow evaporation conditions. ${ }^{116}$ It was revealed by means of various instrumental techniques that organic cations were interlayered within the negatively charged inorganic framework of zinc(II)-aqua cations, sulfate anions and free $\mathrm{H}_{2} \mathrm{O}$ molecules. The overall structure of the solids were stabilized by extensive hydrogen bonding between organic and inorganic moieties and also by $\pi$-stacking interactions among the intercalated aromatics. The as-prepared materials proved to be efficient as catalysts in diasteroselective nitroaldol reactions of various aldehydes with nitroethane.

In an intriguing study by Koner and co-workers, it was reported that instead of intercalating metal complexes into layers of solid materials, transition metal carboxylates with clay-like layered structures could readily be employed as heterogeneous catalysts for epoxidation reactions. ${ }^{117}$ Layered malonato complexes of $\mathrm{Ni}(\mathrm{II})$ and $\mathrm{Mn}$ (II) were prepared by means of a hydrothermal process from the corresponding metal nitrates. The as-prepared materials exhibited a clay-like lamellar structure, in which metal ions bridged together via oxygen atoms of the carboxylato ligands forming the individual layers. Epoxidations of various aromatic and aliphatic alkenes were successfully achieved with the layered transition metal carboxylate catalysts in the presence of $t \mathrm{BuOOH}$ as the oxidant. For olefin epoxidation reactions, 


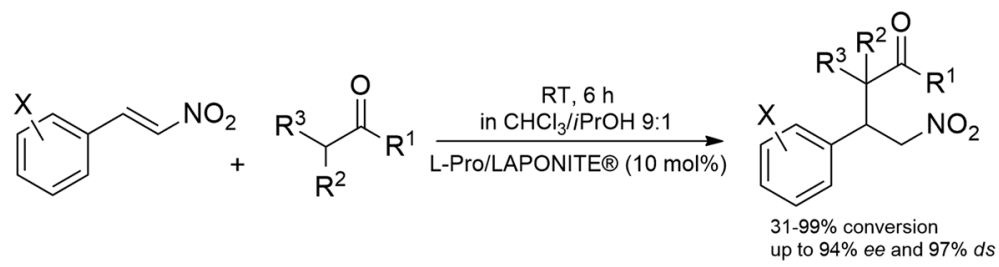

Scheme 24 Surface-improved asymmetric Michael additions with LAPONITE® as a multifunctional organocatalyst carrier. ${ }^{111}$

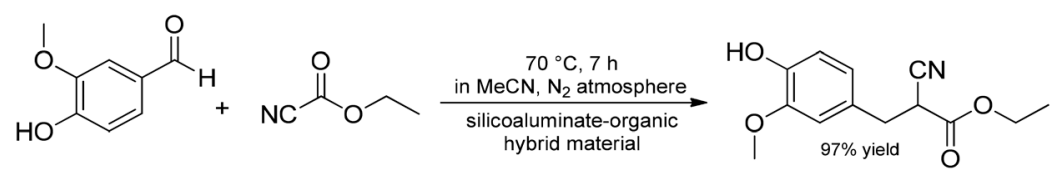

Scheme 25 The catalytic application of a silicoaluminate-organic layered hybrid material in Knoevenagel condensation between ethylcyanoacetate and vanillin. ${ }^{113}$

a cobalt-carboxylate-based layered metal-organic framework material was also found effective as a heterogeneous catalyst. $^{118}$

Amongst heterogeneous silver-catalyzed reactions, the utilization of solid-supported nanoparticles predominates. ${ }^{119}$ On the one hand, silver nanoparticles can readily be immobilized on various surfaces, but, in these materials the catalytic metal is typically bound to the surface through weak forces only, which often gives rise to limited catalyst stability and insufficient robustness. Our research groups therefore reported a novel $\mathrm{Ag}$ (I)Bi(III)-containing hybrid material as an effective and robust heterogeneous silver catalyst. ${ }^{120}$ The layered structure of a naturally occurring mineral called beyerite $\left(\mathrm{CaBi}_{2} \mathrm{O}_{2}\left(\mathrm{CO}_{3}\right)_{2}\right)$ served as the basis of the catalyst design. The material was prepared with the co-hydrolysis of $\mathrm{Bi}\left(\mathrm{NO}_{3}\right)_{3}$ $\cdot 5 \mathrm{H}_{2} \mathrm{O}$ and $\mathrm{AgNO}_{3}$ with the $\mathrm{pH}$ of the synthesis strictly controlled through the temperature of urea hydrolysis. The asprepared solid was fully characterized by means of numerous analytical methods. The catalytic activity of the hybrid material was investigated in the direct nitrogenation of alkynes to organic nitriles (Scheme 27), a useful synthetic transformation which had not been achieved earlier by using a heterogeneous noble metal catalyst. In comparison with commercially available soluble silver catalysts, the AgBi hybrid exhibited remarkable catalytic activity in the reaction of $p$-methoxy phenylacetylene with $\mathrm{TMSN}_{3}$ as a suitable nitrogen source. The effects of various reaction conditions (e.g., temperature, reaction time, solvents and additives) were carefully optimized to access high-yielding nitrile formation from a wide array of aromatic as well as aliphatic alkynes. During the cat-

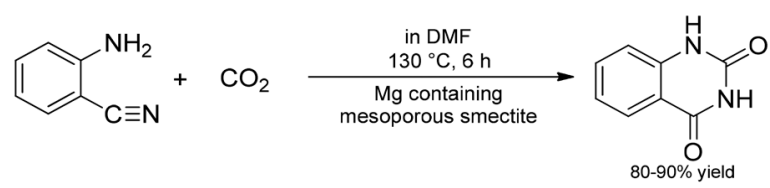

Scheme 26 The application of a magnesium containing mesoporous smectite as a solid base catalyst in the synthesis of quinazoline$2,4(1 H, 3 H)$-dione. ${ }^{115}$ alytic syntheses, the selectivity of the nitrile products was around $90 \%$; only small amounts of 1,2,3-triazole were formed as a non-catalytic side-product. The truly heterogeneous nature of the reaction was corroborated by the completion of the hot filtration test, and the solid catalyst was recycled and reused ten times without loss of its activity or degradation of its structure, thereby providing a sustainable synthetic methodology.

Finally, the application of graphite and graphite-like materials (expanded graphite, graphene and graphene oxide and graphene-LDH composites; for some recent reviews concerning the preparation and properties of these materials, see ref. 121-124) in fine chemical synthesis was surveyed. It was not surprising that in most instances these substances were used as catalytic supports (mostly of metal nanoparticles); however, it was quite unexpected that they acted as the catalysts rarely apart from using certain representatives as photocatalysts, which is not the topic of this current review.

Graphite treated with concentrated sulfuric acid in the presence of $\mathrm{KMnO}_{4}$ and acetic acid resulted in a material with a hierarchically porous structure with acidic centres. ${ }^{125-128}$ This expanded catalyst displayed excellent catalytic activities, selectivities and reusabilities in 1,1-diacetate formation from aldehydes with acetic acid anhydride (14 examples), ${ }^{125}$ methoxymethyl ether formation of primary and secondary alcohols with dimethoxymethane (10 examples), ${ }^{126}$ esterification of isoamyl alcohol with acetic acid ${ }^{127}$ and aldol condensation of $n$-butanal producing 2-ethylhexenal ${ }^{128}$ under moderate reaction conditions.

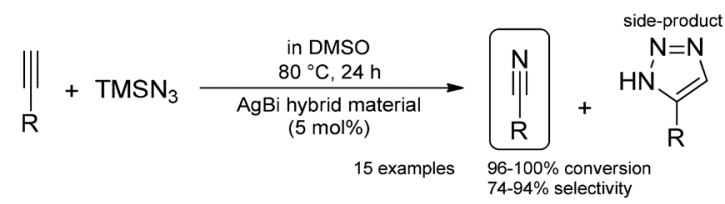

Scheme 27 Heterogeneous AgBi hybrid material-catalysed direct alkyne nitrogenation. ${ }^{120}$ 
From graphene and NiAl-LDH a layered double hydroxide/ graphene composite was prepared. ${ }^{129}$ The $\mathrm{Ni}^{2+}$ ions were in situ reduced to metallic Ni on heating under an inert atmosphere, thus facilitating the formation of highly dispersed $\mathrm{Ni}$ nanoparticles with a uniform size. The resulting Ni nanocatalyst exhibited superior catalytic performance in the liquid phase selective hydrogenation of cinnamaldehyde to hydrocinnamaldehyde.

\section{Summary and outlook}

Layered solid materials hold serious promise as catalysts for the syntheses of fine chemicals (Table 1). As shown herein, the benefits are typically far beyond the evident reusability of such materials, and advantageous catalytic features often arise from the well-defined layered structure itself.

Table 1 Summary of catalysts and applications reviewed herein

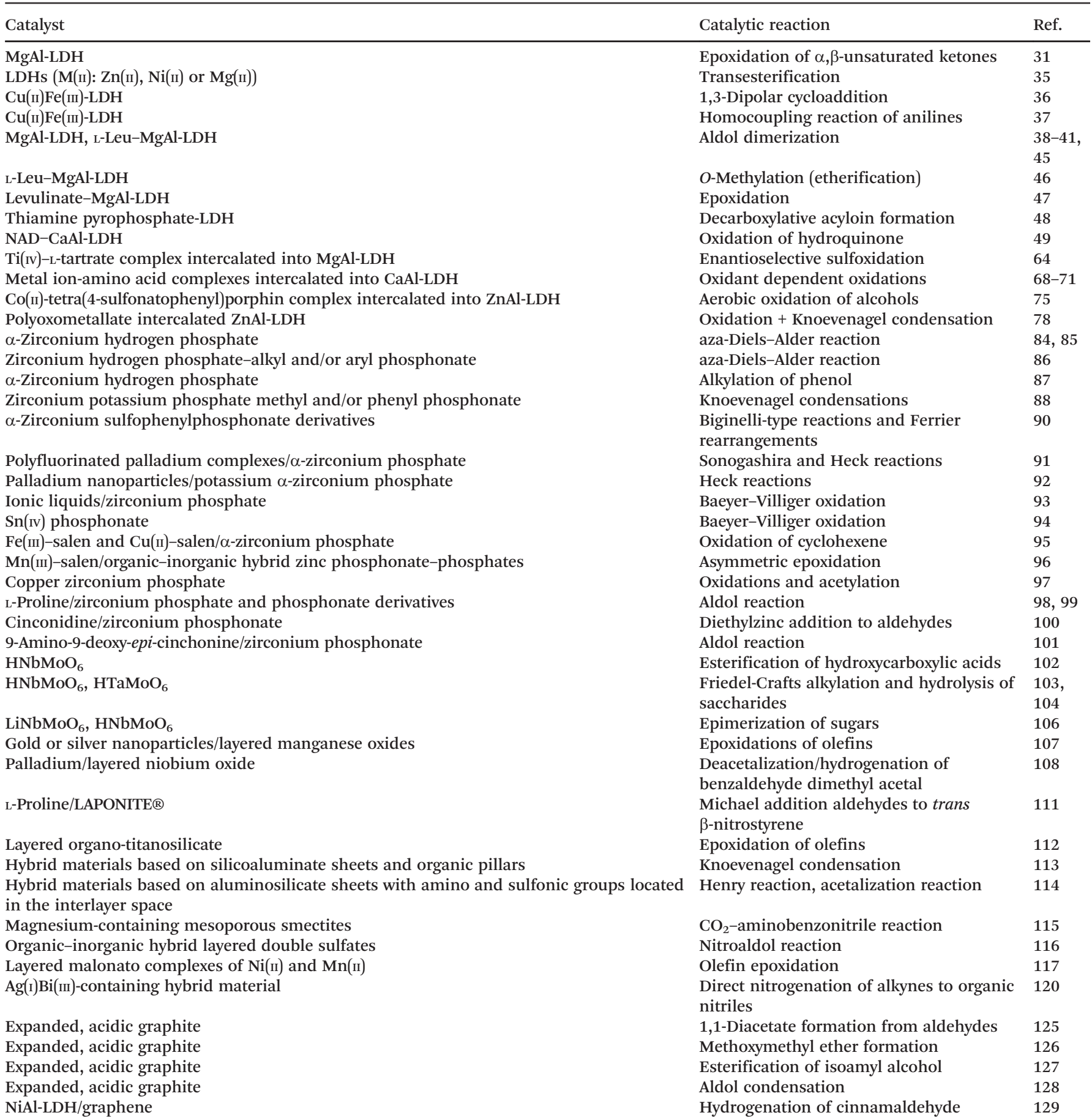


The collected examples prove that pristine LDHs as well as their surface-modified and intercalated varieties are already important players in the field of fine chemical synthesis. Viewing the thousands of LDH-related papers published in recent years, it may be safely anticipated that the development of LDH-related catalysts is not going to stop, and in our view, the emphasis is going to fall on the development of complex catalysts capable of promoting cascade reactions of various types.

As far as other layered materials are concerned, there are already, although in fewer number than LDHs, promising examples, and, again with emphasis on cascade reactions, novel designer catalysts are going to emerge in the near future.

We also believe that the diversity of synthetic reactions catalysed with layered solid materials will significantly broaden in the upcoming years.

\section{Conflicts of interest}

There no conflicts to declare.

\section{Acknowledgements}

This work was supported by the National Science Fund of Hungary through grants OTKA NKFI K 115731 and GINOP2.3.2-15-2016-00013. SBÖ acknowledges the Premium Post Doctorate Research Program of the Hungarian Academy of Sciences.

\section{References}

1 S. J. Mills, A. G. Christy, J. M. Génin, T. Kameda and F. Colombo, Mineral. Mag., 2012, 76, 1289-1336.

2 C. Hochstetter, J. Prakt. Chem., 1842, 27, 375-378.

3 G. D. Evans and R. C. T. Slade, Struct. Bonding, 2006, 119, 1-87.

4 S. Velu, V. Ramaswamy, A. Ramani, B. M. Chanda and S. Sivasanker, Chem. Commun., 1997, 2107-2108.

5 Zs. Ferencz, M. Szabados, M. Ádok-Sipiczki, Á. Kukovecz, Z. Kónya, P. Sipos and I. Pálinkó, J. Mater. Sci., 2014, 49, 8478-8486.

6 T. M. Jyothi, T. Raja, K. Sreekumar, M. B. Talawar and B. S. Rao, J. Mol. Catal. A: Chem., 2000, 157, 193-198.

7 M. Sipiczki, E. Kuzmann, Z. Homonnay, J. Megyeri, I. Pálinkó and P. Sipos, J. Mol. Struct., 2013, 1044, 116-120.

8 C. J. Ellison and K. Shanmuganathan, Polym. Green Flame Retard., 2014, 20, 675-707.

9 W. Wang, J. Zhou, G. Achari, J. Yu and W. Cai, Colloids Surf., A, 2014, 457, 33-40.

10 Y. Wu, Y. Yu, J. Z. Zhou, J. Liu, Y. Chi, Z. P. Xu and G. Qian, Chem. Eng. J., 2012, 179, 72-79.

11 H. C. Greenwell and P. V. Coveney, Origins Life Evol. Biospheres, 2006, 36, 13-37.

12 G.-J. Hu, H.-X. Wang, L. Ling-Yan, M. Pu, J. He and D. G. Evans, J. Phys. Chem. Solids, 2010, 71, 1290-1294.

13 C. del Hoyo, Appl. Clay Sci., 2007, 36, 103-121.
14 T. Baskaran, J. Christopher and A. Sakthivel, RSC Adv., 2015, 5, 98853-98875.

15 Sz. Mészáros, J. Halász, Z. Kónya, P. Sipos and I. Pálinkó, Appl. Clay Sci., 2013, 80-81, 245-248.

16 D. Meloni, R. Monaci, V. Solinas, A. Auroux and E. Dumitriu, Appl. Catal., A, 2008, 350, 86-95.

17 Y. Lu, Z. Zhang, Y. Xu, Q. Liu and G. Qian, Bioresour. Technol., 2015, 190, 438-441.

18 V. Tóth, M. Sipiczki, A. Pallagi, Á. Kukovecz, Z. Kónya, P. Sipos and I. Pálinkó, Chem. Pap., 2014, 68, 633-637.

19 F. Cavani, F. Trifiró and A. Vaccari, Catal. Today, 1991, 11, 173-301.

20 A. Inayat, M. Klumpp and W. Schwieger, Appl. Clay Sci., 2011, 51, 452-459.

21 W. Tongamp, Q. Zhang and F. Saito, J. Mater. Sci., 2007, 42, 9210-9215.

22 Zs. Ferencz, M. Szabados, M. Ádok-Sipiczki, Á. Kukovecz, Z. Kónya, S. Sipos and I. Pálinkó, J. Mater. Sci., 2014, 49, 8478-8486.

23 Zs. Ferencz, Á. Kukovecz, Z. Kónya, P. Sipos and I. Pálinkó, Appl. Clay Sci., 2015, 112-113, 94-99.

24 Zs. Ferencz, M. Szabados, G. Varga, Z. Csendes, Á. Kukovecz, Z. Kónya, S. Carlson, P. Sipos and I. Pálinkó, J. Solid State Chem., 2016, 233, 236-243.

25 M. Szabados, R. Mészáros, S. Erdei, K. Kónya, Á. Kukovecz, P. Sipos and I. Pálinkó, Ultrason. Sonochem., 2016, 31, 409-416.

26 M. Szabados, K. Pásztor, Z. Csendes, S. Muráth, K. Kónya, Á. Kukovecz, P. Sipos and I. Pálinkó, Ultrason. Sonochem., 2016, 32, 173-180.

27 M. Szabados, Cs. Bús, M. Ádok-Sipiczki, Z. Kónya, Á. Kukovecz, P. Sipos and I. Pálinkó, Particuology, 2016, 27, 29-33.

28 M. Szabados, G. Varga, Z. Kónya, Á. Kukovecz, S. Carlson, P. Sipos and I. Pálinkó, Ultrason. Sonochem., 2018, 40, 853-860.

29 M. Milanesio, E. Conterosito, D. Viterbo, L. Perioli and G. Croce, Cryst. Growth Des., 2010, 10, 4710-4712.

30 A. Hayashi and H. Nakayama, Chem. Lett., 2010, 39, 1060-1062.

31 K. Yamaguchi, K. Mori, T. Mizugaki, K. Ebitani and K. Kaneda, J. Org. Chem., 2000, 65, 6897-6903.

32 M. Sipiczki, A. A. Ádám, T. Anitics, Z. Csendes, G. Peintler, Á. Kukovecz, Z. Kónya, P. Sipos and I. Pálinkó, Catal. Today, 2015, 241B, 231-236.

33 P. Sipos and I. Pálinkó, Catal. Today, 2018, 306, 32-41.

34 F. Hamerski and M. L. Corazza, Appl. Catal., A, 2014, 475, 242-248.

35 J. Gandara-Loe, A. Jacobo-Azuara, J. Silvestre-Albero, A. Sepúlveda-Escribano and E. V. Ramos-Fernández, Catal. Today, 2017, 296, 254-261.

36 S. B. Ötvös, Á. Georgiádes, M. Ádok-Sipiczki, R. Mészáros, I. Pálinkó, P. Sipos and F. Fülöp, Appl. Catal., A, 2015, 501, 63-73.

37 S. B. Ötvös, Á. Georgiádes, R. Mészáros, K. Kis, I. Pálinkó and F. Fülöp, J. Catal., 2017, 348, 90-99. 
38 D. Tichit, M. N. Bennani, F. Figueras, R. Tessier and J. Kervennal, Appl. Clay Sci., 1998, 13, 401-415.

39 L. Hora, V. Kelbichova, O. Kikhtyanin, O. Bortnovskiy and D. Kubička, Catal. Today, 2014, 223, 138-147.

40 L. Hora, O. Kikhtyanin, L. Čapek, O. Bortnovskiy and D. Kubička, Catal. Today, 2015, 241, 221-230.

41 O. Kikhtyanin, Z. Tišler, R. Velvarská and D. Kubička, Appl. Catal., A, 2017, 536, 85-96.

42 B. M. Choudary, B. Kavita, N. S. Chowdari, B. Sreedhar and M. L. Kantam, Catal. Lett., 2002, 78, 373-377.

43 Z. An, W. Zhang, H. Shi and J. He, J. Catal., 2006, 241, 319-327.

44 R. Bruckner, in Organic Reaction Mechanisms, Reactions, Stereochemistry and Synthesis, ed. M. Harmata, SpringerVerlag, Berlin Heidelberg, 2010, p. 530.

45 D.-G. Crivoi, R.-A. Miranda, E. Finocchio, J. Llorca, G. Ramis, J. E. Sueiras, A. M. Segarra and F. Medina, Appl. Catal., A, 2016, 519, 116-129.

46 T. Subramanian, A. Dhakshinamoorthy and K. Pitchumani, Tetrahedron Lett., 2013, 54, 7167-7170.

47 N. Candu, D. Paul, I.-C. Marcu, V. I. Parvulescu and S. M. Coman, Catal. Today, 2018, 306, 154-165.

48 M. Baikousi, A. Stamatis, M. Louloudi and M. A. Karakassides, Appl. Clay Sci., 2013, 75-76, 126-133.

49 Sz. Muráth, Cs. Dudás, Á. Kukovecz, Z. Kónya, P. Sipos and I. Pálinkó, J. Mol. Struct., 2017, 1140, 39-45.

50 V. Rives and M. A. Ulibarri, Coord. Chem. Rev., 1999, 181, 61-120.

51 S. He, Z. An, M. Wei, D. G. Evans and X. Duan, Chem. Commun., 2013, 49, 5912-5920.

52 G. Fan, F. Li, D. G. Evans and X. Duan, Chem. Soc. Rev., 2014, 43, 7040-7066.

53 E. Coronado, J. R. Galán-Mascarós, C. Martí-Gastaldo and A. Ribera, Chem. Mater., 2006, 18, 6112-6114.

54 S. Bhattacharjee and J. A. Anderson, Chem. Commun., 2004, 554-555.

55 S. Bhattacharjee and J. A. Anderson, Catal. Lett., 2004, 95, 119-125.

56 S. Bhattacharjee, T. J. Dines and J. A. Anderson, J. Catal., 2004, 225, 398-407.

57 S. Bhattacharjee and J. A. Anderson, Adv. Synth. Catal., 2006, 348, 151-158.

58 S. Bhattacharjee, T. J. Dines and J. A. Anderson, J. Phys. Chem. C, 2008, 112, 14124-14130.

59 L. Dai, J. Zhang, X. Wang and Y. Chen, RSC Adv., 2013, 3, 19885-19888.

60 Y. Liu, Z. An, L. Zhao, H. Liu and J. He, Ind. Eng. Chem. Res., 2013, 52, 17821-17828.

61 B. Monteiro, S. Gago, S. S. Balula, A. A. Valente, I. S. Gonçalves and M. Pillinger, J. Mol. Catal. A: Chem., 2009, 312, 23-30.

62 K. M. Parida, M. Sahoo and S. Singha, J. Catal., 2010, 276, 161-169.

63 H. Shi and J. He, J. Catal., 2011, 279, 155-162.

64 X. Wang, G. Wu, X. Liu, C. Zhang and Q. Lin, Catal. Lett., 2016, 146, 620-628.
65 K. M. Parida, M. Sahoo and S. Singha, J. Mol. Catal. A: Chem., 2010, 329, 7-12.

66 M. Halma, K. A. D. F. Castro, C. Taviot-Gueho, V. Prevot, C. Forano, F. Wypych and S. Nakagaki, J. Catal., 2016, 257, 233-243.

67 J.-H. In, S.-E. Park, R. Song and W. Nam, Inorg. Chim. Acta, 2003, 343, 373-376.

68 G. Varga, Á. Kukovecz, Z. Kónya, L. Korecz, S. Muráth, Z. Csendes, G. Peintler, S. Carlson, P. Sipos and I. Pálinkó, J. Catal., 2016, 335, 125-134.

69 G. Varga, S. Ziegenheim, S. Muráth, Z. Csendes, Á. Kukovecz, Z. Kónya, S. Carlson, L. Korecz, E. Varga, P. Pusztai, S. Sipos and I. Pálinkó, J. Mol. Catal. A: Chem., 2016, 423, 49-60.

70 G. Varga, Z. Timár, S. Muráth, Z. Kónya, Á. Kukovecz, S. Carlson, P. Sipos and I. Pálinkó, Catal. Today, 2018, 306, 42-50.

71 G. Varga, S. Muráth, Z. Kónya, Á. Kukovecz, S. Carlson, P. Sipos and I. Pálinkó, Top. Catal., 2017, 60, 1429-1438.

72 G. Varga, S. Muráth, L. Ujvári, Á. Kukovecz, Z. Kónya, P. Sipos and I. Pálinkó, React. Kinet., Mech. Catal., 2017, 121, 175-184.

73 F. Ullmann and P. Sponagel, Chem. Ber., 1905, 38, 2211-2212.

74 W. Zhou, J. Zhou, Y. Chen, A. Cui, F. Sun, M. He, Z. Xu and Q. Chen, Appl. Catal., A, 2017, 542, 191-200.

75 W. Zhou, P. Tian, F. Sun, M. He and Q. Chen, J. Catal., 2016, 335, 105-116.

76 S. Omwoma, W. Chen, R. Tsunashim and Y.-F. Song, Coord. Chem. Rev., 2014, 258-259, 58-71.

77 T. Li, H. N. Miras and Y.-F. Song, Catalysts, 2017, 7, 260.

78 K. Liu, Y. Q. Xu, Z. Y. Yao, H. N. Miras and Y.-F. Song, ChemCatChem, 2016, 8, 929-937.

79 T. Li, W. Zhang, W. Chen, H. N. Miras and Y.-F. Song, ChemCatChem, 2018, 10, 188-197.

80 G. Alberti, M. Casciola, U. Costantino and R. Vivani, Adv. Mater., 1996, 8, 291-303.

81 (a) M. Pica, Catalysts, 2017, 7, 190; (b) H. Xiao and S. Liu, Mater. Des., 2018, 155, 19-35.

82 K. Melanova, L. Benes, J. Svoboda, V. Zima, M. Pospisil and P. Kovar, Dalton Trans., 2018, 47, 2867-2880.

83 F. Liu, K. Huang, A. Zheng, F.-S. Xiao and S. Dai, ACS Catal., 2018, 8, 372-391.

84 U. Costantino, F. Fringuelli, M. Orrù, M. Nocchetti, O. Piermatti and F. Pizzo, Eur. J. Org. Chem., 2009, 2009, 1214-1220.

85 F. Bellezza, A. Cipiciani, U. Costantino, F. Fringuelli, M. Orrù, O. Piermatti and F. Pizzo, Catal. Today, 2010, 152, 61-65.

86 D. Lanari, F. Montanari, F. Marmottini, O. Piermatti, M. Orrù and L. Vaccaro, J. Catal., 2011, 277, 80-87.

87 A. R. Hajipour and H. Karimi, Appl. Catal., A, 2014, 482, 99-107.

88 O. Rosati, D. Lanari, R. Scavo, D. Persia, F. Marmottini, M. Nocchetti, M. Curini and O. Piermatti, Microporous Mesoporous Mater., 2018, 268, 251-259. 
89 (a) A. Sinhamahapatra, N. Sutradhar, B. Roy, A. Tarafdar, H. C. Bajaj and A. B. Panda, Appl. Catal., A, 2010, 385, 22-30; (b) A. Sinhamahapatra, N. Sutradhar, B. Roy, P. Pal, H. C. Bajaj and A. B. Panda, Appl. Catal., B, 2011, 103, 378-387.

90 (a) O. Rosati, M. Curini, F. Messina, M. C. Marcotullio and G. Cravotto, Catal. Lett., 2013, 143, 169-175; (b) O. Rosati, M. Curini, F. Montanari, M. Nocchetti and S. Genovese, Catal. Lett., 2011, 141, 850-853.

91 N. Lu, K.-Y. Lin, C.-C. Kung, J.-W. Jhuo, Y. Zhou, J. Liu and L. Sun, RSC Adv., 2014, 4, 27329-27336.

92 C. Petrucci, M. Cappelletti, O. Piermatti, M. Nocchetti, M. Pica, F. Pizzo and L. Vaccaro, J. Mol. Catal. A: Chem., 2015, 401, 27-34.

93 (a) G. M. S. R. O. Rocha and C. M. T. Amador, Catal. Lett., 2014, 144, 1197-1209; (b) G. M. S. R. O. Rocha, T. M. Santos and C. S. S. Bispo, Catal. Lett., 2011, 141, 100-110.

94 S. Kirumakki, S. Samarajeewa, R. Harwell, A. Mukherjee, R. H. Herber and A. Clearfield, Chem. Commun., 2008, 5556-5558.

95 (a) S. Khare and R. Chokhare, J. Mol. Catal. A: Chem., 2011, 344, 83-92; (b) S. Khare and R. Chokhare, J. Mol. Catal. A: Chem., 2012, 353-354, 138-147.

96 J. Huang, X. Fu, G. Wang, Y. Ge and Q. Miao, Catal. Sci. Technol., 2012, 2, 1040-1050.

97 (a) A. R. Hajipour and H. Karimi, Chin. J. Catal., 2014, 35, 1982-1989; (b) A. R. Hajipour and H. Karimi, Chin. J. Catal., 2014, 35, 1529-1533.

98 S. Calogero, D. Lanari, M. Orrù, O. Piermatti, F. Pizzo and L. Vaccaro, J. Catal., 2011, 282, 112-119.

99 M. Angeloni, O. Piermatti, F. Pizzo and L. Vaccaro, Eur. J. Org. Chem., 2014, 2014, 1716-1726.

100 X. Ma, Y. Wang, W. Wang and J. Cao, Catal. Commun., 2010, 11, 401-407.

101 W. Wang, X. Ma, J. Wan, J. Cao and Q. Tang, Dalton Trans., 2012, 41, 5715-5726.

102 A. Takagaki, R. Sasaki, C. Tagusagawa and K. Domen, Top. Catal., 2009, 52, 592-596.

103 (a) C. Tagusagawa, A. Takagaki, S. Hayashi and K. Domen, Catal. Today, 2009, 142, 267-271; (b) A. Takagaki, C. Tagusagawa and K. Domen, Chem. Commun., 2008, 5363-5365; (c) C. Tagusagawa, A. Takagaki, S. Hayashi and K. Domen, J. Am. Chem. Soc., 2008, 130, 7230-7231.

104 C. Tagusagawa, A. Takagaki, K. Takanabe, K. Ebitani, S. Hayashi and K. Domen, J. Catal., 2010, 270, 206-212.

105 M. L. Hayes, N. J. Pennings, A. S. Serianni and R. Barker, J. Am. Chem. Soc., 1982, 104, 6764-6769.

106 A. Takagaki, S. Furusato, R. Kikuchi and S. T. Oyama, ChemSusChem, 2015, 8, 3769-3772.

107 M. M. Najafpour, M. Amini, D. J. Sedigh, F. Rahimi and M. Bagherzadeh, RSC Adv., 2013, 3, 24069-24074.

108 N. Lee and Y.-M. Chung, Appl. Surf. Sci., 2016, 370, 160-168.
109 (a) A. Primo and H. Garcia, Chem. Soc. Rev., 2014, 43, 7548-7561; (b) J. Li, A. Corma and J. Yu, Chem. Soc. Rev., 2015, 44, 7112-7127; (c) W. J. Roth, B. Gil, W. Makowski, B. Marszalek and P. Eliasova, Chem. Soc. Rev., 2016, 45, 3400-3438.

110 (a) J. Čejka, G. Centi, J. Perez-Pariente and W. J. Roth, Catal. Today, 2012, 179, 2-15; (b) M. Manuel, M. Cristina and C. Avelino, Angew. Chem., Int. Ed., 2015, 54, 3560-3579; (c) C. Stefan, B. Valerie, L. Benoit and P. Patrick, Curr. Org. Chem., 2017, 21, 779-793; (d) B. E. R. Snyder, M. L. Bols, R. A. Schoonheydt, B. F. Sels and E. I. Solomon, Chem. Rev., 2018, 118, 2718-2768.

111 G. Szőllősi, D. Gombkötő, A. Mogyorós and F. Fülöp, Adv. Synth. Catal., 2018, 360, 1992-2004.

112 H. Zhou, L. Xiao, X. Liu, S. Li, H. Kobayashi, X. Zheng and J. Fan, Chem. Commun., 2012, 48, 6954-6956.

113 A. Gaona, J. M. Moreno, A. Velty, U. Diaz and A. Corma, J. Mater. Chem. A, 2014, 2, 19360-19375.

114 A. Gaona, U. Díaz and A. Corma, Chem. Mater., 2017, 29, 1599-1612.

115 S.-I. Fujita, M. Tanaka and M. Arai, Catal. Sci. Technol, 2014, 4, 1563-1569.

116 O. Kammoun, W. Rekik, T. Bataille, K. T. Mahmudov, M. N. Kopylovich and H. Naïli, J. Organomet. Chem., 2013, 741742, 136-140.

117 R. Sen, S. Bhunia, D. Mal, S. Koner, Y. Miyashita and K.-I. Okamoto, Langmuir, 2009, 25, 13667-13672.

118 J. Zhang, A. V. Biradar, S. Pramanik, T. J. Emge, T. Asefa and J. Li, Chem. Commun., 2012, 48, 6541-6543.

119 X.-Y. Dong, Z.-W. Gao, K.-F. Yang, W.-Q. Zhang and L.-W. Xu, Catal. Sci. Technol., 2015, 5, 2554-2574.

120 S. B. Ötvös, R. Mészáros, G. Varga, M. Kocsis, Z. Kónya, Á. Kukovecz, P. Pusztai, P. Sipos, I. Pálinkó and F. Fülöp, Green Chem., 2018, 20, 1007-1019.

121 D. R. Dreyer, S. Park, C. W. Bielawski and R. S. Ruoff, Chem. Soc. Rev., 2010, 39, 228-240.

122 Q.-L. Yan, M. Gozin, F.-Q. Zhao, A. Cohen and S.-P. Pang, Nanoscale, 2016, 8, 4799-4851.

123 I. Matos, M. Bernardo and I. Fonseca, Catal. Today, 2017, 285, 194-203.

124 Z. Yuan, X. Xiao, J. Li, Z. Zhao, D. Yu and Q. Li, Adv. Sci., 2018, 5, 1700626.

125 T.-S. Jin, G.-Y. Du, Z.-H. Zhang and T.-S. Li, Synth. Commun., 1997, 27, 2261-2266.

126 T.-S. Jin, T.-S. Li and Y.-T. Gao, Synth. Commun., 1998, 28, 837-841.

127 X.-Y. Pang, P. Lv, Y.-S. Yang, H.-L. Ren and F. Gong, E-J. Chem., 2008, 5, 149-154.

128 X. Wu, K. Yao, Z. An and J. Li, Adv. Mater. Res., 2014, 1053, 193-200.

129 R. Xie, G. Fan, Q. Ma, L. Yang and F. Li, J. Mater. Chem. A, 2014, 2, 7880-7889. 